\title{
Karaciğer Hastalıklarında İnvazif OImayan Tıbbi Bilişim Klinik Araştırması: Aksiyon Kuralları
}

\author{
A Medical Informatics Research on Non-invasive Liver Diseases: Action Rules
}

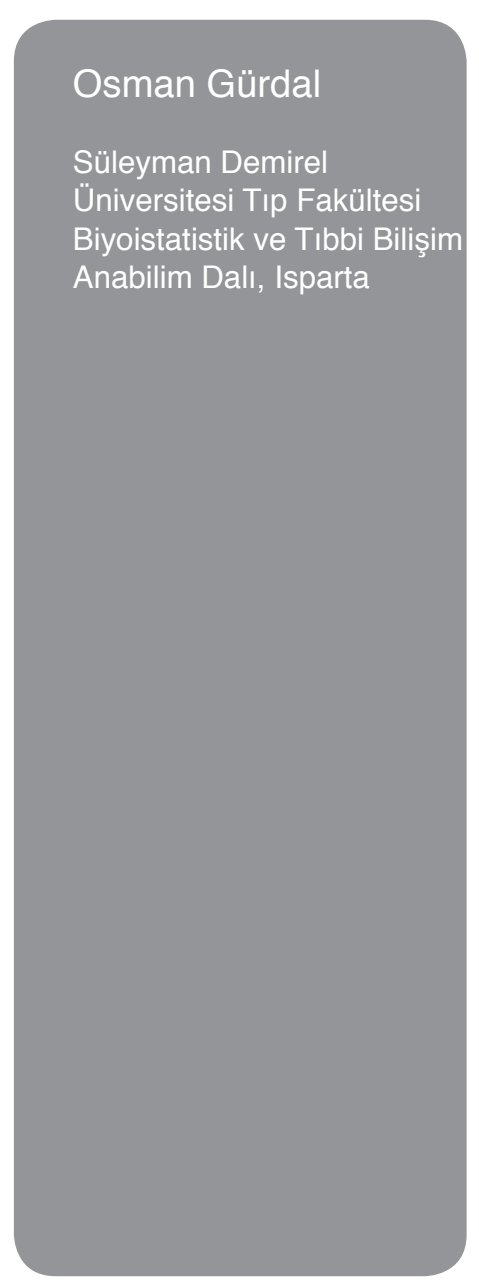

Yazışma Adresi:

Yrd. Doç. Dr..Osman Gürdal

Süleyman Demirel Üniversitesi

Tıp Fakültesi Biyoistatistik ve Tıbbi

Bilişim Anabilim Dalı, Isparta

Email : ogurdal@hotmail.com

\section{Öz}

Klinik Karar Destek Sistemleri (KDDS) sağlık hizmet kalitesini akıllı bir seçimle hekimlere bilgi sunarak arttırmayı amaçlar. Klinisyenler tanı koyma sürecindeki gözden kaçmaların önüne geçmek ve tanıyı gözden geçirmek için KDDS sistemini kullanırlar. Bu sistemler hasta verilerini ve öyküsünü inceleyerek tanı sürecinde hekimlere yardımcı olmak için oluşturulmuştur. Aksiyon kuralları bir tahminden başka bir tahmin için uyumlu bir tahmin yapabilme ve strateji geliştirme yöntemleridir. Bu çalışmamı aksiyon kurallarında nesne-odaklı yeni bir algoritma kullanımını içerir. Bu algoritma elde edilen aksiyon kurallarını önce "aşağıdan yukarı" stratejisi ile başlatır, sonra uzman sistem yardımıyla nesne odaklı veri madeni oluşumunu sağlar. İleri safhasında ise seçilen hastaların verilerini ayrıştırıp en üstün nitelikteki test verilerini çıkarır. Sonuç olarak elde edilen verileri hastanın öyküsü ve fiziksel muayene bulguları ile karşılaştıır. Bu sistem nesne odaklı olarak tasarlanmış ve diğer sistemlere göre daha hızlı çözümleyici ve güçlüdür. Bu nesne odaklı yapıda işlev yapan algoritma daha kısa sürede ve tekrarlamalar olmadan sonuca ulaşmayı sağlar. Hekimler tam isabetli olmayan bir tanıyı aksiyon kuralları algoritması yardımı ile yeniden sınıflandıılarak hastaya tanı koymada ve hastalık yönetme sürecinde önemli bir katkı sağlayabilir.

Anahtar Kelimeler: Aksiyon kuralları, tıbbi bilişim, invazif olmayan karaciğer hastalıkları, klinik karar destek sistemleri.

\begin{abstract}
Clinical Decision Support Systems (CDSS) can be used ingeniously to assist clinicians and health care providers make clinical decisions. Physicians and decision makers utilize a CDSS to establish better diagnoses and to revisit it in terms of refining final outcome. Action rules are defined and extracted patterns that they can predict coherent and congruent strategies from one state to another. This study is a new algorithm for action rules based on object-orientation. It initiates as a "bottom-up breath-first strategy" and later it constitutes object-driven data with an expert system. Then it mines the patents' data selected with the highest values of attributes to get a desired effect on a decision feature. This object-driven strategy, where the redundancy is eliminated, is faster than the classical strategy for identifying action rules. Action rules can be implemented as an assistant for physicians as well as for impartial diagnoses to be validated by reclassification.
\end{abstract}


Keywords: Action rules, medical informatics, noninvasive liver diseases, clinical decision support systems.

\section{Giriş}

Bilgisayar tabanlı Klinik Karar Destek Sistemleri (KKDS) hekimlerin tanı, tedavi ve prognoz için öneriler sunan yardımcı karar verme araçlarıdır. Bu sistemler iyi tasarlandıklarında sağlık alanındaki karmaşık klinik karar verme mekanizmasını desteklemektedir. KKDS'ler hem hizmet sunumunda hem de sağlık harcamalarının azaltılmasındaki katkısı nedeniyle dikkat çekmeye başlamıştır. Bu nedenlerle KKDS'ler sağlık alanında karar verme mekanizmaları arasında yer almıştır. (1,2). Aksiyon Kuralları (AK) Bilgi Keşfi (BK) alanında bilgisayaraltyapılı KKDS'ler çerçevesinde klinik uygulamalarda işletilebilir, güvenli, adapte edilebilir ve yöntemsel yararlı stratejilerdir (2-4). Bilgi Keşif Veritabanları (BKV) ham verileri aksiyona çevirerek sonuca ulaşmayı sağlar (5). Başlangıç araştırmalarında keşfedilen örüntüler ve formülleştirilen çözümleri özellikle sağlık alanında tam bir çözüme otomatik olarak ulaşmamaktaydı (6). Bu nedenle daha sonra "yarı-otomatik analiz sistemleri" oluşturulmuştur. Yine de bu sistemler hem zaman alıcı ve hem de önyargılı sonuçlar oluşturmaktaydı. Bu durumunun düzeltilmesi ve özellikle önyargılı (biased) algoritma sistemini ortadan kaldırmak için destekleyici karar verme sistemi oldukça önemli bir araç olarak ortaya çıkmıştır. Bu gelişmeler ile birlikte hekimlerin klinik karar verme sürecinde KKDS otomatik olarak devreye girmekte ve hekime alternatifler sunarak hataları azaltmayı amaçlamaktadır. Bu kuramda aksiyon kurallarının temel çalışmaları arasında keşfedilebilir örüntülerin ölçüm yapabilmesi ve iyi bir temelin olması önemli bir gözlemdir (7). Sonuç olarak veriler ile uzman bir sistemden oluşan giriş (input), aksiyon kuralları algoritmasını oluşturarak istenen veya özel bir görevin ortaya çıkmasını ve sonuç vermesini sağlar. Başka bir deyişle, veri tabanı madenciliği ile oluşturulan aksiyon örüntüleri kullanıcıya istediği bir işlemde uygulama imkânı sağlar. Bu kurallarda en önemli kriterlerden biri nesne-odaklı örüntüler arasındaki ilişkilerin yakın bölünmeleri ile aksiyon tasarım planı arasında çalışılabilecek bir analitik ayırımdır. Pratik olarak aksiyon kurallarında keșfedilebilir örüntüler önyargısız kararlar ve değerlendirmelerdir. Öte yandan bir klinisyenin klinik karar verme sürecinde bazı sübjektif kararlar vermesi mümkündür ve olabilmektedir.

Karaciğer hastalıklarında bir artış eğiliminin olması, hastalığın başlangıç safhasında doğru tanı konulmasının zor olması ve bu hastalıklarda erken teşhisin önemli olması, bu pilot çalışmada karaciğer hastalıklarının seçilmesinin en önemli sebeplerdendir. Aynı zamanda karaciğer rahatsızlıklarında altın standart olan tanı, biyopsi sonucu ile belirlenir fakat biyopsi zorunlu durumlar dışında tercih edilmeyen girişimsel-invazif bir işlemdir. Bu nedenle çalışmamızda bilgisayar programı yardımı ile girişimsel olmayan bir ortamda karaciğer hastalıklarına tanı koyulması ve tedavi planlanması üzerine çalışılımıştır.

\section{Algoritma}

\subsection{Aksiyonlaştırmada Simgelemeler}

Takip eden simgelemeler makale boyunca kullanılır. Bir bilgi sistemi (7) demek istiyoruz ki $S=(I, A, V)$, ve orada:

$I=\left\{X_{1}, X_{2}, \ldots X_{j}\right\}$ belirlenmiş sınırlı bir nesne grubu, $A=\left\{a_{1}, a_{2}, \ldots a_{j}\right\}$ belirlenmiş sınırlı bir nitelik grubu, $V=\left\{v_{1}, v_{2}, \ldots, v_{k}\right\}$ ise belirlenmiş sınırlı bir nitelik değerleridir.

$S$ bilgi sistemi Tablo 1'de gösterilmektedir. Bu tabloda $D$ karar verme niteliklerini, $B, C$ ve $E$ sütunları ise durum niteliklerini temsil eder. Örneğin, $x$ tablodaki ilk sütunu göstermekte ve $B\left(x_{1}\right)=0$ dır. Tabloda dört tane nitelik bulunmakta ve bunlar $A=\{B, C, E D\}$. Bu nitelikler iki şekilde sınıflandırılır: kondisyon ve karar. Kondisyon nitelikleri $B, C$ ve $E$ ve karar niteliği ise $D$ dir. Kondisyon nitelikleri değişmez ikiye ayrılır. Birincisi hastanın deri rengi veya kalıtsal yapısı gibi değişmez (stable) olan $A_{S t}$ ve sigara içme alışkanlığı veya yeme bozukluğu gibi esnek (flexible) olan $A_{F I}$ dir. Bu algoritmada bir nesneye verilen bir değer zaman içerisinde değişmez ise o nitelik (attribute) kararlıdır yani değişmezdir. Diğer yönden kullanılan nitelik ise esnek veya değişkendir. Bu nitelikler $d(I)=\{k:(\exists x \in I)$ $[d(x)=k]\}$ olarak belirlenir ve benzer koşullu nitelikleri 


\begin{tabular}{cllll} 
Nesneler & $\begin{array}{l}\text { B } \\
\text { değişmez }\end{array}$ & $\begin{array}{l}\text { C } \\
\text { esnek }\end{array}$ & $\begin{array}{l}\text { E } \\
\text { esnek }\end{array}$ & $\begin{array}{l}\text { D } \\
\text { karar }\end{array}$ \\
\hline$x_{1}$ & 0 & 2 & 0 & I \\
$x_{2}$ & 2 & 2 & 0 & I \\
$x_{3}$ & 2 & 2 & 2 & W \\
$x_{4}$ & 2 & 3 & 0 & I \\
$x_{5}$ & 2 & 1 & 1 & W \\
$x_{6}$ & 3 & 3 & 1 & N \\
$x_{7}$ & 3 & 4 & 0 & $N$
\end{tabular}

oluşturur. Böylece aksiyon kuralı madenciliği aksiyon oluşturabilen ve kurucu (constructive) işlemleri oluşturur; bunlar istenen ve istenmeyen olarak ikiye ayrilır. Tablo 1'de $\{C, E\}$ nitelikleri esnek, $\{B\}$ niteliği değişmez ve $\{D\}$ niteliği ise karar niteliğinde analiz edici veya hekimin tanı sonucunun değişmiş olduğunu bekleyecektir -bir hastanın tanı ve tedaviden sonra iyileşme durumu gibi.

\subsection{Aksiyon Kuralları}

$\mathrm{Bu}$ çalışma kullanıcılara bir listelik olan nitelik değerleri sağlar ve bu değerler istenmeyen bazı nesneleri değiştirerek onları istenen hale getirebilir. Bir diğer ifade ile, oluşturulan nitelik değerleri kurucu bir yapı görevini yaparak istenen ve istenmeyen nesneleri ortaya çıkarır. Algoritma bazında bu yoldan hareketle, örneğin bir hekim sadece bir hastasının iyileşme engellerini bilmek yanında, o hastasının iyileşme zamanın önemini de bilmek ister. Illaveten bir hekim hastasının iyileşme hızını ve engelleyici aksiyonları hakkında da bilgi sahibi olmak ister. Aksiyon kuralları böyle durumlarda istenmeyen olayları irdeleyerek onların istenen bir durum haline de gelmesini sağlar. Bu kuralların kavramı detaylı olarak (8 ve referansındaki Frawlet et al., 1991) ifade edilmektedir.
Nesne odaklı bir aksiyon kuralı olan $p$ bir bilgi sistemi olan S'de:

$p=\left[\left[\left(a_{1}=\omega_{1}\right) \wedge\left(a_{2}=\omega_{2}\right) \wedge \ldots \wedge \quad\left(a_{q}=\omega_{q}\right)\right]\left(b_{1}, a_{1} \rightarrow \beta_{1}\right)\right.$ $\left.\wedge\left(b_{2}, a_{2} \rightarrow \beta_{2}\right) \ldots \wedge\left(b_{p}, a_{p} \rightarrow \beta_{p}\right)\right] \rightarrow\left[\left(d, k_{1} \rightarrow k_{2}\right)\right]$, orada ki $\left\{b_{1}, b_{2}\right.$, $\left.\ldots, b_{p}\right\}$ esnek ve $\left\{a_{1}, a_{2}, \ldots, a_{\}}\right\}$kararlı nitelikler $S$ içinde ifadesiyle tanımlanır. Buradaki yaklaşım benzer nitelikteki iki hasta bilgilerinin karşılaştırılması aksiyon kurallarını oluşturmaya başlayacaktır. Algoritmanın oluşturulması bazında bu durum ise: sol destek, $\operatorname{suppL}(p)=\operatorname{Card}\left[\operatorname{Dom}_{s}\left(P_{L}\right) / \operatorname{Card}[I]\right.$, sağ destek, $\operatorname{suppR}(r)=\operatorname{Card}\left[\operatorname{DomS}\left(P_{R}\right)\right] /, \operatorname{Card}[U]$, ve güven, $\operatorname{Conf}_{S}(p)=\left(\operatorname{Card}\left[\operatorname{Dom}_{S}\left(P_{L}\right)\right] / \operatorname{Card}\left[\operatorname{Dom}_{S}\left(V_{L}\right]\right)\right.$ $\left(\operatorname{Card}\left[\operatorname{Dom}_{S}\left(P_{R}\right)\right] \quad / \operatorname{Card}\left[\operatorname{Dom}_{S}\left(V_{R}\right)\right]\right)$, olarak ifade edilmektedir. Daha detaylı bilgiye $(4,1)$ 'den ulaşılabilinir.

\subsection{Algoritma Tanımı}

$\mathrm{Bu}$ araşıımanın amacı aksiyonlaştırmayı objektif (unbiased) bir şekilde analiz etmektir. Nesne odaklı çalışma birden fazla grup yapısı oluşturarak bu yapıları veri seti üzerinde matematiksel olarak test eder. Bütün bunlarla beraber karar verici niteliklerden sübjektif olmayı tamamen (\%100) atmak mümkün değildir. Aksiyon kuralları ilk çalışma bazında bilgi alanına bağıı olduğu için bu durum önemlidir. Bütün bunlara rağmen nitelikleri ikiye bölmek değişmez 
mi veya esnek mi tamamen kullanıcıya bağlıdır. Bu durum gerçekten önyargılıdır. Örneğin, kanama, sigara içme, karaciğer hastalarında safra kanalı tıkanıklıkları gibi durumlar kullanıcı tarafından manipüle ve kontrol edilebilir. Bu esnek bir durumdur. Diğer yönden işitme, yaşlanma ve cinsiyet gibi durumlarda herhangi bir önyargılı-sübjektif olma durumu yoktur, bu değişmez bir yapıdır. İlaveten algoritma tasarımı üzerindeki kısıtlamalar sistem $S$ için seçilecek nesneleri belirlemede değişmez nitelikler tarafından belirlenir. Örneğin hekimlerin klinik karar verme ve akıl yürütmeleri sürecinde kendine özgü yaklaşımları vardır. Bunlar değişebilen önyargılı niteliklerdir ve kullanıcıya göre bir durumdan diğer bir duruma değişebilmektedir.

\subsection{Ana Çerçeve}

Algoritmayı kurmak için geniş ölçekli (breadth-first) arama tipi starateji kullanılarak sınıflandırma öncesi çıkarımı ortadan kaldırır $(4,5,8,9)$. Burada önemli olan nesne odaklı olduğu için fazlalığa yer verilmez. Algoritma hazırlanırken; referans karar tablosunu ikiye böl ve istenmeyenleri uzaklaştırma ile aksiyon yapılabilen örüntülerin kurulması olarak iki durum gerekir.

Karar verme sistemi $S$ Tablo 2'de görüldüğü gibi $T s_{1}$ ve $T s_{2}$ olmak üzere iki alt tabloya ayrılır. Karar verme nitelikleri de $d \approx D$ and $d \approx H$ olarak ifade edilir. Algoritmanın kurulma aşamasında örneğin iyileşmeyen hastalar ve/veya hastaların verileri çalışmaya alınmadığından bu hastalar ile ilgili karar değerleri $N$ hesaplamaya dahil edilmez ve $d \approx N$ olarak uygulanır. Daha detaylı bilgi için (4 ve referanslarına bakınız). İlaveten, karar verme atomları oluşturulup bunlardan benzeri olmayan ve minimum destek sağlama koşuluyla seçilenler karar verme mekanizmasına dahil edilirler. Eğer seçilecek atomların değerleri başlangıç değerlerinde düşük ise negatif değer verilmekte ve sistemden uzaklaştırılırlar. Sonuçta algoritma sol destek, sağ destek ve güven başlangıç değerlerini dikkate alarak seçilen atomları değerlendirir ve karar mekanizmasında pozitif değerlileri atomların içinden en yüksek güven değerlilerine sahip olanlardan seçer. Böylece aksiyon kuralı yüksek güvenilirlikle seçilen atomlardan kurulmuş olur ve algoritmasal iterasyon şekliyle

\begin{tabular}{|c|c|c|c|c|c|c|c|}
\hline Nesneler & $\mathbf{a}$ & b & C & Nesneler & a & b & c \\
\hline \multicolumn{4}{|c|}{ - - - - - - - - - - - - - - - - - - - - - - - - - } & \multicolumn{4}{|c|}{ - - - - - - - - - - - - - - - - - - - - - } \\
\hline \multirow{3}{*}{$\begin{array}{cc} & \mathbf{x}_{1} \\
T s_{1} & \mathbf{x}_{2} \\
& \mathbf{x}_{4}\end{array}$} & 0 & 2 & 0 & \multirow{3}{*}{$T s_{2}$} & 2 & 1 & 2 \\
\hline & 2 & 2 & 0 & & \multirow[t]{2}{*}{2} & \multirow[t]{2}{*}{1} & \multirow[t]{2}{*}{1} \\
\hline & 2 & 3 & 0 & & & & \\
\hline
\end{tabular}

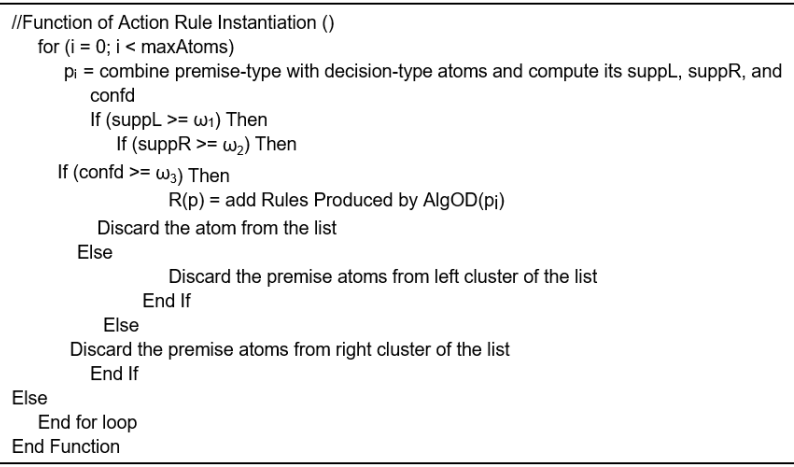

Şekil 1.

Nesne odaklı algoritma AlgOD. 
devam eder. Şekil 1'de nesne odaklı algoritmanın genel kuramı ve çalışma şekli gösterilmiştir.

\section{Aksiyon Kurallarının Uygulanması}

Aksiyon kuralı uygulaması literatürde oldukça tartışılmaktadır. Bir aksiyonun kuralının biçimsel olarak tanımlanması (10) tarafından yapılmıştır. Bu çalışmamızda temel veri tabanı olarak HEPAR veri sistemini kullandık. HEPAR bünyesinde karaciğer hastalarına ait 860 kayıt kullanılmıştır. Hastaların kayıtları başından itibaren, biyopsi, laparoskopi ve klinik takipler ile ayrıntılandırılmıştır. HEPAR veri tabanı Polonya Bilim Akademisi ve Yüksek Öğretim Tıp Merkezi'nin Biyosibernetik ve Biyotıp Mühendisliği tarafında kurulmuş ve geliştirilmiştir. Karar verme kurallarından oluşan bu veri tabanındaki kurallar hasta bilgilerini hepatoloji veri tabanından çıkaran bir veri sistemidir. Nesne odaklı bu çalışmamız önceleri aksiyon kuralları stratejisi şekliyle oluşturulup sonra (11) tarafından tanıtımış, daha sonraları $(12,2)$ tarafından bilinen çiftlerden sınıflandırma kuralları olarak geliştirilmiştir. Ras ZW ve Darzinska A (2) çalışmalarında aksiyon kurallarının bir çift sınıflandırma şekliyle kurulmasının gerekli olmadığını ve tek sınıflandırma kurallarının da aynı sonucu verdiğini kanıtlanmışlardır. Bu çalışmaların temelini teşkil eden algoritma basit Learning from Examples bases on Rough Sets (LERS) şekliyle kurulmuş ve daha sonraları Discovering Extended Action Rules (DEAR) $(3,13)$ ve Action Rules Discovery Based on Agglomerative Strategy (ARAS) aksiyon kuralları şekliyle geliştirilmiştir. Nesne odaklı çalışmamız istenmeyen fazlalıkları (redundancy) sistemden uzaklaştırıp daha hızlı ve daha az zaman kaybetme olanağına yer vererek sistem akışını daha güçlü (robust) hale getirir (4).

\subsection{Deneysel Çalışmalar}

Çalışmamızda kullanılan HEPAR veri tabanı yaklaşık 758 kayıtlı hastanın karaciğer hastalıkları ile ilgili verilerine sahiptir. Bu verilerden 106 tane nitelik elde edilmiştir. Bu niteliklerden 31 tanesi sınıflandırılmış laboratuvar testleridir ve bunlar: normalüstü, normalve normalaltı nitelikler şeklinde oluşturulur. Bu niteliklerin 14 tanesi kararlı niteliklerdir. Biyopsi alınarak iki adet $\mathrm{HBsAg}$ ve $\mathrm{HBcAg}$ antijenine rastlanmış (doku içerisinde) ve bunlar invazifdir. Karar verme nitelikleri ise 7 adet olarak çıkarılmış ve bu değerler: I - şiddetli (acute) hepatit, Ila - az şiddetli akut (hepatit B ve C), Ilb - az şiddetli (alkol kullanımı), Illa - iyileştirilebilen kronik hepatit, IIIb - iyileştirilemeyen kronik hepatit, IV - siroz hepatit ve $V$ - karaciğer kanseri olarak tanımlanır.

Karaciğer hastalıklarının tanısı genel olarak şikayetin öğrenilmesi, anamnez alınması, fizik muayene yapılması, laboratuvar tetkikleri, görüntüleme yöntemleri ve histopatolojik incelemeler ile ilerletilir. Biyokimyasal tahliller karaciğer hastalıklarının tanısında büyük rol oynar ve hastanın fizik muayenesi ve anamnezi ile birlikte değerlendirilmelidir. Hastalık tanısı için kullanılan bu tetkikler arasında Ultrasonografi (USG) önemli bir yer tutar. Özellikle karaciğer kitleleri, safra kanallarının durumu ve safra kesesi taşlarının teşhisini koymakta USG önemlidir. Bununla birlikte girişimsel olmayan bu tetkiklerin karaciğerde inflamasyonunu göstermede bir yararı yoktur. Öte taraftan karaciğer biyopsisi hasta için önemli bir risk taşımaktadır. Bütün bunlarla birlikte karaciğer inflamasyonunda ve karaciğerde fibrozis oluşumlarının tespitinde girişimselolan - invazif biyopsi kaçınılmaz olabilir.

Çalışmamızda hastaların yeniden sınıflandırılmasını amaçlamaktayız. Özellikle Ilb kategorisindeki bir hastanın invazif olmayan bir tedavi metoduyla I kategorisine (Ilb $\rightarrow I$ ) ve Illa kategorisindeki bir hastanın da yine I kategorisine ( IIla $\rightarrow$ I) inerek değerlendirilmesini hedeflenir. Bu amaçla da aksiyon kurallarını yeniden sınıflandırıyoruz. Buradaki yeni metodumuz da daha önceki çalışmalara göre yeniden sınıflandırmayı nesne odaklı - fazlalık aksiyonları kullanmadan sınıflandırma ile yapılmasıdır. Kullandığımız HEPAR veri tabanında temel tıbbi testler ve sürekli alkol kullanımı yapan hastalar sübjektif nitelikler taşıyabileceğinden ve \% 90'dan fazla değeri olmayan (değerleri kaybolmuş) nitelikler çalışmalarımıza alınmamıştır.

Bundan sonraki strateji RSES (14) programı kullanılarak invazif olmayan bir test grubu çıkarılmıştır. Bulunan bu değerler aşağıdaki tanımları içermektedir. 
$P$ kümesi $=\{b, s, e, o, w, s k, h v, s p, h h, j p, e d, c y, s l$, bp, ap, pi, tc, da\} d-deducts yapılan çalışmalardan bir tanesi olup aşağıdaki değerleri içermektedir:

$b=$ kanama, $s=$ subikterik hafif sarılık, $e=$ geğirme, 0 = engel (örneğin safra taşları), $w$ = ağırlık kaybı, sk = sigara kullanma, hv = viral hepatit öyküsü (kararlı), $s p=$ geçmişteki cerrahi müdahaleler (kararlı), hh = hastane öyküsü (kararlı), jp = gebelik sarılığı, ed = eritematozus dermatitis, cy = kist, $s \mathrm{l}=$ keskin sınırlı karaciğer (kararlı), ap = alkalen fosfataz, pi = protrombin indeksi, tc = bütüm kolestrol, da = karar niteliği.

\section{Sonuç ve İleri Çalışmalar}

Nesne odaklı algoritma uygulamasında 8 adet aksiyon kuralları oluşturulmuş olup bunlardan en yüksek güvenirlik dereceli olan 3 aksiyon kuralları aşağıda verilmiştir:

1. $[(h h, 2) \wedge(h v, 2) \wedge(s l, 2)] \wedge(e, 2 \rightarrow 1) \wedge(t c, 2 \rightarrow 1)$ $\Rightarrow(d a, I I l a \rightarrow I)$

$\mathrm{Bu}$ kural en yüksek güvenirlik dereceli olarak açıklar ki: hastane öyküsüne dayanarak geçmişte hastanede kalan ve ameliyat olmayan bir hastanın fiziksel muayenesinde karaciğerinin keskin sınırlı olmadığı belirlenmiştir. Kural açıklar ki: bu hastanın eğer geğirme ve safra akışındaki engeller ortadan kaldırılırsa, kolesterol seviyesi normale döndürülür. Böylece hastanın durumu yeniden sınıflandırılarak Illa sınıfından I (IIla $\rightarrow$ I) sınıfına indirilmiş olur.

$$
\begin{aligned}
& \text { 2. }[(h h, 2) \wedge(s l, 2) \wedge(s p, 1)] \wedge(0,2 \rightarrow 1) \wedge(w, 2 \rightarrow 1) \Rightarrow \\
& (d a, I I I A a \rightarrow I)
\end{aligned}
$$

Bu ikinci kural en yüksek güvenirlik dereceli olarak tanımlar ki: hastane öyküsüne dayanarak geçmişte hastanede kalan ve ameliyat olmayan bir hastanın fizik muayenesinde karaciğerinin keskin sınırlı olmadığı belirlenmiştir. Kural açıklar ki: eğer safradaki tıkanıklıklar ortandan kaldırıldığında ve normal kilo sağlandığında hastanın durumu IIla'dan l'e (IIla $\rightarrow I)$ indirilerek yeniden sınıflandırılır.
3. $[(h h, 2) \wedge(s l, 2) \wedge(s p, 1)] \wedge(e, 2 \rightarrow 1) \wedge(0,2 \rightarrow 1) \wedge$ $(s, 2 \rightarrow 1) \Rightarrow(d d, I I A \rightarrow I)$

Bu üçüncü kural da en yüksek güvenirlik dereceli olarak belirler ki: : hastane öyküsüne dayanarak geçmişte hastanede kalan ve ameliyat olmayan bir hastanın karaciğerinde keskin sınırlar olmadığı belirlenmiştir. Kural: eğer geğirme ve safrasındaki engeller ortadan kaldırıldığında subikterik hafif sarılık normale döner ve hastanın durumun yeniden sınıflandırılarak IIla seviyesinden I (IIla $\rightarrow$ I) normal seviyesine iner.

Bu makale aksiyon kurallarının tıbbi araştırma alanında özellikle hepatoloji dalında bilgisayar kullanılarak nasıl bir otomasyon yapılabileceğini ve çalışmalarda en son durumun nesne odaklı (objectdriven) algoritma kullanımın en kısa yol olduğunu öz ve kısa bir şekilde sunar. Çalışmamız bilgi temelli mantıksal koşulların nesnelere bağlanarak uzman sistem yardımıyla aksiyon kurallarının belirlenmesine ve uygulanmasına dayanır. Bu, bilgisayar temelli bilgi sistemin ve oluşturulan akıllı algoritmanın hasta odaklı tedaviler için hekime yardımcı olabilecek bir araç ve gereç olarak da tanımlanabilir. Çalışmamızda en önemli karar verme mekanizmalardan biri, başlangıç değerlerinin akıllı bir şekilde kontrol edilmesidir. Bu alandaki temel karar verici olan uzman sistemin akıllı talimatı ve oluşturduğu bilginin hatasız olması gerekmekte ve çalışmalar bu alanda yoğunlaşmaktadır. Bu sahadaki gelecek çalışmalar nitelik değerlerinin uzman sistemindeki desteği, karar vermede ve zaman harcamında değerlerin etkisi, kısa süre zarfında hastanın tedavisine yönelik bilginin oldukça doğru ve güvenilir olması gibi uygulama çalışmaları yapılmalı ve değerlendirilmelidir. Nesne odaklı olan algoritmanın bilimsel kargaşalığının daha az olması için çalışmalar yapılmalıdır. Bu da klinik verilerinin ve hasta tanımlarının daha net olmasına yardımcı olacaktır. Kayıp verilerin, doğru olmayan mantıksal çıkarımların, ilaveten kodlama hatlarının daha az seviyelere indirgenmesi gelecek ilave çalışmalar olarak verilebilir.

Teşekkür: Makalenin Türkçe yazılım kurallarını düzeltip edit eden Dr. Giray Kolcu'ya teşekkür ederim. 


\section{Kaynaklar}

1. Ras ZW, Tsa LS. Discovering extended action-rules (System DEAR). Intelligent Information Systems. Proceedings of the IIS' 2003 Symposium, Advances in Soft Computing, Springer; 2003; 6(8) p. 293-300.

2. Ras ZW, Dardzinska A. Action rules discovery - a new simplified strategy. Foundations of Intelligent Systems, Esposito F. et al. (Eds.), LNAI, No. 4203 Springer. 2006; 445-453.

3. Ras ZW, Tzacheva A, Tsay, LS, Gurdal O. Mining for interesting action rules. Proceedings of IEEE/WIC/ ACM International Conference on Intelligent Agent Technology, Compiegne University of Technology, France. 2005 Sep 19-22; Compeigne, France p.187-93. 4. Gürdal O, Dardzinska A. New Approach to Clinical Medicine by Action Rules. Int. Journal of Development Research, 2017; 7(1): 11032-9.

5. Dardzinska A. Action rules mining. Studies in Computational Intelligence, Springer Publication, Springer-Verlag, Berlin: Springer-Verlag; 2013.

6. Agrawal R, Imielinski, T, Swami A. Mining association rules between sets of items in large databases. In: Buneman P, Jajodia S, editors. Proceedings of ACM SIGMOD International Conference on Management of data; 1993 May 25-28; Washington DC. New York: ACM; 1993; p. 207-16.

7. Pawlak Z.. Information systems - theoretical foundations. Information Systems Journal. 1981 6, 205-218.

8. Ras ZW, Dardzinska A. Action Rules Discovery without pre-existing classification rule. In: ChienChung C, Grzymala-Busse JW, Ziarko, WP, editors. Proceedings of 6th International Conference on Rough Sets and Current Trends in Computing; 2008 Oct 23-25; Akron, Ohio.p Berlin: Springer-Verlag, 2008. p. 181-90.

9. Hajja A, Ras ZW, Wieczorkowska A. Hierarchical object-driven action rules. J. Intell. Inf. Syst. 2014; 42 (2): 207-32.

10.Geffner H, Wainer J. Modeling action, knowledge and control. In:Prade H, editor. ECAI 98: Proceedings of 13th European Conference on Artificial Intelligence; 1998 August 23-28; Brighton UK. New York: WileyBlackwell; 1998 p. 532-6.

11. Adomavicius G, Tuzhilin A. Discovery of actionable patterns in databases: The action hierarchy approach.
Proceedings of the 3rd International Conference on Knowledge Discovery and Data Mining; 1997 Aug 1417. The AAAI Press; 1997. p. 111-4.

12. Tsay L-S, Ras ZW. Action rules discovery: system DEAR2, method and experiments. Journal of Experimental \& Theoretical Artificial Intelligence, 2005; 17(1-2): 119-28.

13.Bobrowski, L. 1992 HEPAR: Computer system for diagnosis support and data analysis. Prace IBIB 31, Institute of Biocybernetics and Biomedical Engineering, Polish Academy of Sciences, Warsaw, Poland.

14.http://logic.mimuw.edu.pl/ rses/about.html 